\title{
The Past, Today, and the Future of Human Papilloma Virus Vaccines
}

\author{
Mustafa KARA ${ }^{1}$, Mehmet BALCI ${ }^{2}$, Neziha YILMAZ ${ }^{2}$ \\ ${ }^{1}$ Bozok University Faculty of Medicine, Department of Obstetrics and Gynecology \\ ${ }^{2}$ Bozok University Faculty of Medicine, Department of Infectious Disease and Microbiology, Yozgat, TURKEY
}

\begin{abstract}
Human papilloma virus (HPV) is the most common sexually transmitted viral infection. The clinical spectrum of disease ranges from asymptomatic infection, to benign warts (primarily caused by low-risk HPV genotypes 6 and 11) to invasive malignancy. Over $70 \%$ of cervical cancer associated with the high-risk genotypes 16 and 18. According to the GLOBOCAN 2002 investigation which is held by International Agency for Research on Cancer the cervical cancer incidence in Turkey is 4.5 in 100.000. It was seen 1364 new cervix cancer case and 726 deaths due to cancer in the same year. In Turkey, cervical cancer is the 9th most common cause of cancer death in women. This review will highlight the science behind HPV vaccines, recent advances in HPV prophylactic vaccine development, the most recent clinical trial results and important issues we need to consider prior to implementation of the vaccine in Turkey.
\end{abstract}

Keywords: Human Papilloma Virus, Cervix cancer, HPV vaccines

ÖZET

\section{Human Papilloma Virüsü Aşısının Geçmişi, Bugünü ve Geleceği}

Human papillomavirus HPV) en sık görülen seksüel yolla bulaşan hastalık etkenidir. Hastalı̆ı̆ klinik spektrumu asemptomatik infeksiyondan, primer olarak düşük riskli HPV 6 ve 11 genotipleri tarafından oluşturulan benign siğillere ve invazif malignansiye kadar değişir. Tüm servikal kanserlerin \%70'inden fazlası yüksek riskli genotipler olan 16 ve 18 ile birliktedir. Uluslar arası Kanser Araştırma Ajansı'nın 2002'de yaptığı GLOBOCAN araşıımasına göre Türkiye'de servikal kanser insidansı yüz binde 4.5'tir. Aynı yıl 1364 yeni serviks kanseri vakası ve 726 kansere bağlı ölüm görülmüştür. Serviks kanseri Türkiye'de kansere bağlı ölümlerde 9. sıradadır. Bu inceleme yazısı HPV aşılarını ardındaki bilimsel gerçeklere, HPV koruyucu aşı gelişimindeki son ilerlemelere, en son klinik çalışmaların sonuçlarına ve aşının Türkiye'de kullanıımasının öncesinde önemli meselelere ışı tutacaktır.

Anahtar Kelimeler: Human Papilloma Virus, Serviks kanseri, HPV aşıları 


\section{INTRODUCTION}

Zur Hausen and his friends isolated HPV type 6 DNA from condylomas for the first time in the beginning of $1970 \mathrm{~s}^{1} \mathrm{HPV}$ types are classified in terms of whether they cause cervical neoplasm or not. HPV types which are rarely seen in pre-invasive or invasive cervical neoplasm are classified as low risk, and those which are determined in high-level Cervical Intraepithelial neoplasm (CIN) and in cancer are classified as high-risk HPV. Low-risk HPV prototypes are HPV 6 and 11, high-risk HPV prototypes are HPV 16 and 18 (Table 1). HPV 16 and 18 are together determined in $90 \%$ of CIN 2 and 3, and $70 \%$ of invasive cervical cancers. According to epidemiological data, HPV has been found positive in $85 \%$ of both anal and perianal cancers, in $80 \%$ of vulvar and vaginal cancers and in about $50 \%$ of penile cancers. ${ }^{2,3}$

The fact that there is a strict etiological connection between high-risk HPV and cervical cancer has accelerated the researches in order to find prophylactic and therapeutic vaccines. The researches phase $2 b$ and phase 3 show that the vaccine is reliable and tolerable. But, lots of issues such as; the protection time of the vaccine, beginning age of vaccinating, the vaccinating strategy in pregnancy, the cost of vaccinating still have been discussed. This study aims at compiling current information about prophylactic HPV inoculations.

\section{The Immunology of Human Papilloma Virus}

HPV is a deoxyribonucleic acid virus (DNA) without envelope and double chained which belongs to papovaviridae family, consisting 72 capsomers, and it has got more than 200 serologic types. More than 40 HPV types have been found out using viral DNA probs. HPV has got relationship not only with cervix cancer but also with genital warts, anal cancer, vul- var and vaginal cancer, oropharynx cancer, larynx and digestive system cancer, and even with juvenile laryngeal papillomatozis. HPV type 6 and 11 are responsible for $90 \%$ of genital wart in men and women. HPV type 16 and 18 are responsible for $70 \%$ of anal cancers in men and women. HPV infection is the most common sexually transmitted disease in the United States of America. It is estimated that 20 million people are infected with HPV, and the number of annual new cases is 6.2 million in USA. Seventy five percent of the people who are active sexually have been infecting with HPV in any period of their lifetime. ${ }^{4}$ Although, most of the HPV infections limit themselves without giving any clinical symptom and finding, the infections consisting oncogenic HPV types can cause cervical cancer in women. ${ }^{5}$ The relationship between HPV and cervix cancer is the strongest casual relationship that has ever been determined. According to the data of International Agency of Research of Cancer, HPV test is positive in $99.7 \%$ of all the cervical cancers. The high rate of HPV positiveness shows that HPV infection is needed in growing cervix cancer. But, the natural course of HPV infection and the fact that it proceeds as infections on the wane explain why HPV infection is not sufficient to develop a cancer., ${ }^{2,6}$

\section{Infection}

HPV can infect sexually or not sexually. It has been shown that usage of condom can reduce transmitting up to $70 \%$, but anyway, it doesn't protect exactly. It is claimed that it spreads by public swimming pools, saunas and bathroom, but that could not be proved. ${ }^{7.8}$ It is said that it infects from mother to newborn vertically, or by the help of underwear, surgical glove, biopsy apparatus, but it could not be completely put forward. ${ }^{9}$ Men acquire the infection and infect in HPV transition. Young age, the excess in number of

Table1. HPV types and lesions (More common types are written bigger).

\begin{tabular}{|ll|}
\hline Lesion Type & Human Papilloma Virus (HPV) Types \\
\hline Cervical and anogenital Cancers & $16,18,31,33,35,39,45,51,52,54,56,58,59,66,68,69$ \\
Cervical Intraepithelial Neoplasia (CIN) & $6,11,16,18,26,30,31,33,34,35,39,40,42,43,45$, \\
& $51,52,53,54,55,56,57,58,59,61,62,64,66,67,68,69,70$ \\
& $71,73,74,79,81,82,83,84$ \\
Condyloma accuminata & $6,11,42,44,51,53,83$ \\
\hline
\end{tabular}




\begin{tabular}{ll} 
Table 2. Functions of HPV genes. \\
$\begin{array}{ll}\text { Open reading } \\
\text { frame }\end{array}$ & Function \\
\hline E1 & Viral replication \\
E2 & Viral transcriptionand regulation \\
& of replication \\
E3 & Function unknown \\
E4 & Interaction with cytoskeletal proteins, \\
& M2 activation \\
E5 & Oncoprotein; p53 inactivate, \\
E6 & telomerase activate \\
& Oncoprotein; pRB inactivate, p21 and \\
E7 & p27 activate \\
& Receptor protein replication \\
E8 & Major viral capsid protein \\
L1 & Minor viral capsid protein \\
L2 & Beginning point of DNA replication \\
LCR &
\end{tabular}

sexual partner, sexual partner with CIN and being uncircumcised are among the risk factors of infection. ${ }^{3}$

\section{Natural Course of Infection and Pathogenesis}

HPV genome consists of double spiral DNA, $8 \mathrm{~kb}$ long. 'Open reading frame' (ORF) area which encodes viral functional proteins is on a single spiral DNA and separated in 3 areas: long control region (LCR), early (E) and late (L) area. The genes of HPV which encode viral and functional proteins and the functions of these genes are summarized in Table 2. Late ORF area encodes capsid proteins of the virus within its life circle. Early area functions as regulator in DNA replication and reactivation of the life circle of virus. ${ }^{7}$ Mature squamose creationists are required for replication of viral particles. Active HPV infection starts when infectious particles arrive at the basic layer of epithelium. Infection L1 and L2 starts when capsid proteins connect with host cell receptors. And then, the virus starts to use DNA replication systems of host cell for its own replication. Viral genome persists in nucleus and is transferred into other new cells by mitosis of the cells. The critical molecules during the process of viral replication and cellular transformation are E6 and E7. E6 and E7 respectively link tumour suppressor gene p53 and retinoblastoma gene (pRB). The expansion of the virus for genomic integration generally occurs in E1/E2 area. When E2 which behaves swaging against E6 and E7 collapses, E6 and E7 become over expression and this results in inactivation of p53 and pRB. Variations in different types of HPV oncogenity seems to be connected with the differences in inactivation of tumour suppressor genes and the connection of E6 and E7 with p53 and $\mathrm{pRB}$. The low risk types do not lead that kind of changes.

As a result of the fact that tumour suppressor genes do not indicate their effects, cell cycle cannot be controlled. Genomic instability increases, oncogenic mutations accumulate, the control of cell cycle disappears and eventually the process towards cancer begins. Since these processes are non-litic, meanwhile the inflammatory processes affect less. As a result, HPV stays for a long time without being realized by host immune system. ${ }^{8}$

According to data of Center for Disease Control (CDC), acquired genital HPV infection will be seen in at least $80 \%$ of the women up to 50 . Seventy five percent of the new HPV infections appear among 1524 ages. Most of these infections are temporary and recede spontaneously. Seventy percent of it will clean within a year, and $90 \%$ of it will clean at the end of 2 years. Although it isn't exactly known by which mechanism the viral infection is eradicated, the cellular immune response is thought to be effective in this subject. Since HPV particles free by way of normal desquamation, the way of cytopathic death do not play role in immunity. Humoral response is very less occurring against HPV infections. Cellular immune response is important in removing the virus. HPV persistence occurs in the people whose immune system is swaged. Pre-invasive and invasive lesions can develop in some women having HPV with persistent infection. The frequency of persistence is higher in some types (HPV 16, 18, 31, 45). After 5 years of persistence with HPV 16 , the risk of CIN is $40 \%$. HPV is positive in $99.7 \%$ of cervix with squamose cellular cancer and in $95 \%$ of adenocancer, HPV 16 type in squamose cellular cancer, HPV 18 in adenocancer is seen more frequently. The women with persistent oncogenic HPV infection are under high risk in terms of pre-invasive and invasive lesions. The longer HPV infection lasts, the more difficult the patient gets well. The other related factors are: age ( $>20$ years), infection with some types of HPV, immune suppression, tobacco and other sexually transmitting diseases..$^{10}$ The process of HPV infection from persistent HPV to CIN2 and CIN3, and 
finally to cancer takes about 15 years. And this helps the scanned population with preventing cervical cancer.

\section{HPV Vaccines}

After the relationship between the oncogenic HPV types and cervical cancer was found out, there was an increase in the number of studies on Human Papilloma Virus (HPV) vaccines, and a quadrivalent vaccine consisting particles suchlike virus belonging to HPV 6, 11, and 18 was put on the market in June, 2006, and in 2007, a double vaccine developed against HPV 16 and 18 was put on the market. HPV vaccine is important for primary protection, for the secondary protection, annual follow-ups have critical importance. As for protection from cervix cancer, HPV vaccine and Papanicoleau smear (Pap smear) follow-up are significant. Since HPV vaccine doesn't cure the existent disease, smear scanning should be gone on the people vaccine with HPV inoculation. The aim of inoculation is to prevent the woman against infection. It is not an application used instead of cancer scanning.

HPV which is generally caught between the ages of 15-20 turns into CIN at the end of 5 years process, and cervical cancer within 20 years. 'Primary Protection' is provided with the inoculation done before the first contact with the virus, and 'Secondary Protection' is provided with the inoculation done after the virus was taken. The vaccines developed against HPV infections are prophylactic and therapeutic vaccines. Prophylactic vaccines are developed to prevent the healthy people from HPV infections and related complications. As for therapeutic vaccines, they are still research period; they intend to realize remission and regression of lesions in cases with pre-cancerous lesion and cervix cancer. Therapeutic vaccines have got two types: one is to prevent accumulation of the virus in infected people, and the other is to retrograde the tumour developed in cervix. Prophylactic vaccines are 3 types: type 1 , type 2 and type 3 . Type 1 vaccine contains virus-like proteins (VLP) consisting of L1 capsid antigen; type 2 vaccine includes VLP consisting of L1 and L2 fusion proteins; and type 3 vaccine contains reverse self peptides. Therapeutic vaccines are synthesized against E6-E7 and E1-E2 oncoproteins of HPV.

\section{Therapeutic Vaccines}

The aim of therapeutic vaccines is to destruct the tumours producing E6 and E7 proteins. Therefore, they carry out tumour cell lysis stimulating cytotoxic $\mathrm{T}$ lymphocytes. They are divided into 5 groups according to the type of production.

1. Vectorial based vaccines: Their immunogenicity are high, but security anxiety and previous immunization are their disadvantages.

2. Peptide based vaccines: Their advantages are reliability and applicable, and the fact that it must have adaptability with Human Leucocyte Antigen (HLA) in order to be applied is their disadvantage.

3. Protein based vaccines: They are reliable and don't have limitation of HLA. But, it is warned that their cellular immunity is weak.

4. DNA originated vaccines: Their application, storing and transportation are easy. They can easily be applied in a doubtful antigenic expression. But, their immunogenicity is weak.

5. Autolog dendritic cell based vaccines: They are highly immunogenic. But, their production and bioprolificacy are difficult. ${ }^{11}$

In a study controlled at random about Therapeutic vaccines, a vaccine formed against HPV 16 E6 and E7 (CerVAX 16 TM) in $20 \mu \mathrm{g}$ and $60 \mu \mathrm{g}$ doses was given to 24 cases with CIN 1 and CIN 3, and $200 \mu \mathrm{g}$ dose placebo drug was given to the remaining 7 cases, and it was claimed that the vaccine was reliable and immunogenic, and it formed decreasing in HPV 16 viral load in infected tissue. ${ }^{12}$ In a phase 2 study carried out by Einstein and his friends, HspE7 (Stressgen) vaccine developed against HPV 16 E7 and micro bacterial heat shock protein was applied 3 doses in 0,1 and 2nd months in 31 CIN 3 cases, and after 4 months observation, a full resolution in the rate of $46 \%$ and a partial resolution in the rate of $19 \%$ was obtained. ${ }^{13}$

Finally, Therapeutic HPV vaccines are at research level. The number of cases with different therapeutic vaccines in clinical studies is limited. Therapeutic approaches which will be sensitive the immunity around the lesion are studied about therapeutic vaccines affecting by increasing the response of cytotoxic $\mathrm{T}$ cell (Table 3$)^{14}$.

\section{Prophylactic Vaccines}

The aim of prophylactic vaccines is free viral particles. They are produced against capsid antigens L1 or L2. They contribute to the humoral immunity increasing the production of neutralizer antibody. The particles suchlike viruses (VLP) which are obtained by infection of L1 genes in HPV DNA in plasmid are collected spontaneously. Each of the particles suchlike virus consists of 72 capsomers formed by L1 mo- 
Table 3. Therapeutic vaccines ${ }^{13}$

\begin{tabular}{llll|}
\hline Firm & Antigen & Type & HPV Type \\
\hline Xenova/ Cantab & E6, E7 & Live recombinant vaccine virus (TA- HPV) & 16,18 \\
Transgene & E6, E7, IL2 & Live recombinant vaccine virus (MVA- HPV- IL2) & 16 \\
Xenova/ Cantab & L2, E6, E7 & Fusion protein (TA- CIN) & 16 \\
Cantab & L2, E7 & Fusion protein (TA- GW) & 6 \\
Stressgen & E7 & Fusioon protein: mycobacterial heat shock protein & 16 \\
CSL & E6, E7 & Fusion protein (CerVax 16) & 16 \\
Cytel & E7 & Peptide & 16 \\
University of Leiden & E7 & Peptide & 16 \\
Zycos & E7 & DNA microparticule (Zyc 101) & 16 \\
Medigene & L1, E7 & Chimeric virus like proteins & 16 \\
NCl & L1, L2, E7 & Chimeric virus like proteins & 16 \\
\hline
\end{tabular}

lecule. Thus, the derived vaccine does not consist of viral DNA, and it is not infectious and oncogenic. It shows strong immunogenic activity and the obtained immunity is long-term and authentic.

\section{Prophylactic HPV accines are types:}

1. Quadrivalent vaccine: This vaccine developed against HPV type 6, 11, 16 and 18 consists of VLP L1. It is produced by Merck Company (Gardasil@) and approved by American Food and Drug Administration (FDA) on 8 June 2006. It has been available in Turkey since April 2007, and it is inoculated as 3 doses in 0,2 nd and 3rd months.

2. Bivalan vaccine: It is developed against HPV type 16 and 18 , produced by Glaxo Smith Kline Company (Cervarix ${ }^{\circledR}$ ). It is inoculated as 3 doses in 0,1 st and 6th months.

Comparison about both vaccines has been done in Table 4. HPV vaccines are tolerated well; they cause to be obtained good response of antibody. Therefore, it decreases the prevalence of HPV infection and clinical diseases related with HPV. HPV and smear tests are not required before inoculation. The vaccine can be applied to those whose smear result is normal. Inoculation should be as possible as early in girls (age of 9); it is recommended that it should be applied to the girls at the age of 11-12 as a routine. The girls who are 13-16 years old and not inoculated are supposed to be inoculated. There is no positive or negative publication on inoculation of the women bet- ween the ages of 19 and 26. Its application on over twenty six years is controversial and it should be evaluated individually. There is no consensus on inoculation of men and it is claimed that the best time for inoculation 3 years before sexual relation. Scanning of cervix cancer and smear test pursuit should be gone on in the same way as in non-inoculated people.

\section{Prophylactic Vaccine Studies}

Three random prophylactic vaccine studies as one monovalent (phase 2), and then quadrivalent (phase 3 ) and one bivalent (phase 2) have been completed until now. ${ }^{15,16,17}$ In PATRICIA study (PApilloma TRIal against Cancer In young Adults) published by Harper et al. Lancet journal in 2004, the effectiveness of bivalent vaccine against HPV 16 and 18 has been searched. In this study, 3 doses bivalent vaccine was given to 560 of 1113 women whose smear tests and HPV 16 and 18 were negative and who had less than 6 sexual partners, the remaining 553 patients were given placebo and they were observed for 27 months in terms of HPV DNA test, cytology and serum antibody levels; finally, it was found out that the vaccine was $100 \%$ effective in prevention of persistent HPV infection. ${ }^{16}$ When the same study lasted for 4,5 years, the protection of bivalent vaccine was $98 \%$, and it was stated that it was reliable and provided crosswise protection. ${ }^{18}$ The final analyze of PATRICIA was done in July 2009 and the inoculation of 15-25 age group who had never met with HPV before was done to reflect general population. A group of 8093 pe- 
Table 4. Comparison of prophylactic HPV vaccines

\begin{tabular}{|c|c|c|}
\hline & Quadrivalent vaccine & Bivalent vaccine \\
\hline Vaccine type & HPV $6,11,16,18$ VLP L1 capsid protein & HPV 16, 18 VLP L1 capsid protein \\
\hline Production & Fermented & Insect cells (baculoviruses) \\
\hline \multirow[t]{4}{*}{ Content } & 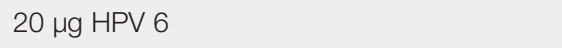 & 20 mg HPV 16 \\
\hline & $40 \mu \mathrm{g} \mathrm{HPV} 11$ & $20 \mu \mathrm{g} \mathrm{HPV} 18$ \\
\hline & 40 mg HPV 16 & \\
\hline & $20 \mu \mathrm{g} \mathrm{HPV} 18$ & \\
\hline Adjuvant & $20 \mu \mathrm{g}$ Aluminium hydroxiphosphate sulphate & $\begin{array}{l}500 \mu \mathrm{g} \text { Aluminium hydroxide with } \\
50 \mu \mathrm{g} \text { deacilated monophosphoryated } \\
\text { lipid A (AS04) }\end{array}$ \\
\hline Vaccine application periods & 0,2 and 6. months & 0,1 and 6. months \\
\hline
\end{tabular}

ople who had never met with HPV and had negative cytology were compared with another group of 8069 people who had never been inoculated and the protection rate was found $98.1 \% .9319$ of those who were sexually active, and had HPV vaccine inoculated in deficient dose (1 dose was done) and their HPV positiveness was ignored were inoculated. When compared with the control group of 9325 people who were not inoculated, it was pointed out that the vaccine was $30.4 \%$ effective in the group with CIN 2, and in the rate of $33.4 \%$ in the group of CIN 3 .

5822 patients whose oncogenic HPV was negative (serology positive) and didn't have sexual intercourse were inoculated and when they were compared with the group of 5819 who were not inoculated, it was found that it was $70.2 \%$ effective in CIN 2, and $87 \%$ in CIN 3. The vaccine was $54 \%$ effective in CIN 2 formed with the other oncogenic types, and it was said that its crosswise protection was also good..$^{19}$

Villa, et al. examined the effectiveness of quadrivalent vaccine. They gave 3 doses vaccine to 276 of 551 women who had less than 4 partners and negative for HPV $6,11,16,18$, and to the rest of 275 were given placebo, at the end of 36 months follow-up, they reported that persistent HPV developed in only $0.14 \%$ of the inoculated ones (4 cases), $13 \%$ (36 cases) in control group, and no clinical disease developed in the inoculated group. FUTURE I (Female United To Unilaterally Reduce Endo/Ectocervical disease) is a phase III study which is multicentered, multinational and consists of 5455 cases between the ages of 16-24. The people who were not scanned for HPV before randomisation were applied vaccine and placebo in 0, 2nd, and 6th months, the effectiveness against HPV was found 100\%. (Observation time 1.7 year). FUTURE II is a phase III study covering 12167 cases between the ages of 15-26 in USA. In the 17 th month following the vaccination, the effectiveness for HPV 16 and 18 was determined as $100 \%$ in more than 10.000 cases. $^{20}$

It is considered that the combination of cytological scanning with HPV vaccination will give the best rate of cost-benefit result. ${ }^{21}$ A protection strategy based on only HPV vaccination can decrease cervix cancer cases, but can't eliminate it. It is stipulated that the best strategy will be 3 times cytological scanning application in 5 years time beginning at the age of 30 following the vaccination of preadolescences. The benefits of the vaccine are limited in CIN cases. The observation should continue after vaccination. Vaccination can cause a false protection feeling. Vaccination is not curative for genital warts and cervical cytological changes formed before. Testing is not recommended before inoculation. Because, HPV DNA test indicates the current infection, doesn't determine HPV infection having been had before. Thus, HPV typecasting increase the costs of vaccination programme (America Gynaecology and Obstetrics Association, ACOG, 2006).

\section{The Matters to be Paid Attention in Choosing Vaccination Program}

The girls should be vaccinated before they come to the age of sexually active. While the rate of sexual relationship among the girls before 13 years old is $7 \%$ in the USA, the same rate in Brazil is $32 \%$. Epidemiological studies show that most of women are 
infected months after first sexual activity. Therefore, it is thought that the vaccination in childhood or at the ages of 12-14 just before the sexual activity starts will be the most appropriate strategy. ${ }^{22}$ The probability of meeting with all types in early ages is very less. The effectiveness of the vaccine will be very less if it is applied to the women with multi partners in the ages. Owing to the fact that it could decline the infection, it is claimed that the men should also be vaccinated in terms of public health. In addition, vaccination of men has protection effect against genital warts, non-cervical cancers and anal cancer. ${ }^{23,24}$ It hasn't got a licence to apply to men in USA. A licence to vaccine men between 9 and 15 was given but its fee isn't covered by the state.

It is said in the International Papilloma Virus (IPV) Congress that the quartet vaccine has effectiveness up to 9.5 years. Bivalent vaccine is said to form very high antibody response even after 7.3 years. While neutralizing antibody titre is at the peak level in 7 th month, it decreases gradually by 24 th month, and then titre becomes stable. Whether Rapel doses are necessary or not is not known. To be able to say that the vaccine has preventive effect against cancer, more than 20 years should pass, since cervical cancer develops in 20 years after the first contact. ${ }^{23,24}$ When antibody titre formed by bivalent vaccine is compared with quadrivalent vaccine, the level of antibody in double vaccine is 2.3-4.8 times higher for HPV type 16 and 6.8-9.1 times higher for type 18 .

Ideally, the girls who are 12-14 years old should be vaccinated in 3 doses, and cytological scanning of cancer should go on as it is in those without vaccination. Scanning starts at the age of 21 three years later after the sexual relationship begins. Conventional Papanicoleau (Pap) test or liquid base cytology is applied. Conventional Pap test is performed once a year until the age of 30 , after then, once in 2 or 3 years is applied to those who have at least 3 negative tests. HPV test is applied once in 3 years to those with negative HPV.

The cost should be considered when the inoculation of girls at the age of 12-14 is nationwide in question. While a dose of quartet vaccine which should be inoculated in three doses is 120 American dollars, total price of 3 doses of double vaccine is 160 American dollars. The cost which will be brought by vaccination of the girls throughout Turkey is important. But, after inoculation, the costs of smear test, the number of patients sent to colposcopy, the rate of patients' follow-up, surgical operations will be serious decline.
Bivalent vaccine doesn't cover all the types, but has protection against the types of $16,18,31$, and 45.13 more HPV types should be added to the vaccine to prevent all types causing cancer. Pentavalence (consisting five HPV types) is considered to prevent $83 \%$ of cervix cancers potentially, and heptavalence (seven) prevents $87 \%$ of the cases. However, it is estimated that quadrivalent (quartet) vaccine could give the most benefits in the study of cost-effectivity. ${ }^{25}$

The number of cases vaccinated is quiet less and any increase hasn't been observed in the frequency of congenital anomaly in these cases during pregnancy. In 15 cases in group of 1244 people who were vaccinated during the quartet inoculation program, and became pregnant in a month, and in placebo group with 1272 people 16 cases of congenital anomaly were determined, and no difference was observed between the two groups. According to these results, the vaccine has been evaluated in B category by FDA. But, the vaccine is not recommended during pregnancy because the number of cases is not enough. A pregnancy test is not required before inoculation. The inoculation program continues after pregnancy. Whether vaccine antigens and antibodies pass to milk or not isn't known. Since the vaccine includes inactive virus particle, there is no objection in applying to women in lactation. The quartet vaccine can be applied in lactation.

The quartet vaccine should be done in 3 doses in 0 , 2nd, 6th months, and double vaccine should be done in 3 doses in $0,1 \mathrm{st}$, and 6 th months. It should be taken pains to be at least 4 weeks between the first and second doses for people who weren't vaccinated properly. The time between the second and third doses should be at least 12 weeks. The dose should be repeated for people whose shots were done insufficient or who were vaccinated before anticipated time. In case of cessation in vaccinating, the schedule is not started again. If the cessation is after the first dose, the second dose is applied immediately, and 12 weeks is waited for the third dose. If the aforementioned forgotten dose belongs to the third vaccine, the missing dose is applied at once.

\section{Side Effects of the Vaccine}

One of the most speculated topics about the vaccine is side effects. The people who are vaccinated in the USA are observed by the help of a system called 'VAERS' (Vaccine Adverse Event Reporting System) and the developing side effects are reported. Post-inoculation side effects can be local (such as ache, swelling, and eritem), systemic (frequently fever) and the probability of serious side effect is less than 
$0.1 \% .15441$ side effect announcements were made totally until January 2009. 43 demises (8 of them in Europe) and 204 life threatening side effects were declared. None of these demises accepted because of the vaccine. Two demises happened within 15 days after the inoculation. Seven demises were related with traffic accident, three demises with overdose by mistake or suicide, two demises with pulmoner emboli or deep vein thrombus, two demises with sepsis, one each with cancer and aritmy and one case with asphyxsia. The most frequent side effects are feeling short term ache in the infected area, allergic reactions and syncope. Syncope is particularly seen in adolescents and young women. Therefore, the patient should have a rest for 15 minutes after application and observed. It is estimated that the serious effects are seen less since only $1 \%$ of all the effects are reported to VAERS.

\section{Ethical Issues About the Vaccine}

5 years time requires developing CIN after the first contact with HPV, and 15-20 years time requires developing cancer from CIN. Thus, to be able to say that the applied vaccine is really effective, it needs at least 20 years of protection. The vaccines available in the market now have got 8.4 years protection time at most. Therefore, we need time to say something about the net effect. ${ }^{19}$

Cellular immunity is important in HPV eradication. However, the vaccine only increases humoral immunity. ${ }^{8,10,12}$

Phase 2 (FUTURE) study results about quadrivalent vaccine were disclosed in 2007, but the vaccine got FDA approval on 8 June 2006.

It is argued that 1 woman in each 2 minutes on the World, and in Turkey 2 women are killed every day because of cervix cancer. However, while cervix cancer is the third in developed countries, it is the ninth in Turkey. Three doses bi-valance vaccine costs 160 American dollars. Considering that there are 10 million girls who need vaccinating between the ages of 9-26 ages, a national vaccination program for Turkey will cost 1.6 billion American dollars. To spend 1.6 billion dollars in order to reduce the rate of cervix cancer to 1 in 10000 from 4.5 in 10000 in Turkey is not considered logical at first, but considering the treatment cost of cervix cancer and the complications and human life, we think that the cost can be ignored..$^{26}$

HPV has got more than 200 types. More than 40 types of it cause infection in humans. The present vaccine in market now provides $70 \%$ protection. In other words, even the best vaccine does not include spectrum completely, and we believe that much more HPV types should be added to the vaccine and the cost should be reduced.

\section{CONCLUSION}

The strongest cause and effect relationship which has ever been determined is available between HPV and cervix cancer. HPV DNA has been determined positive in $99.7 \%$ of all the cervix cancer cases. One woman in each 2 minutes throughout the World, and in Turkey 2 women are killed every day because of cervix cancer. ${ }^{27}$

HPV vaccine has been licensed for the purpose of being used in girls/women between the ages of 9-26. Clinical studies show that the vaccine is reliable and immunogenic in this age group. The studies on the women who are between 16 and 26 years old indicate that the vaccine effective against cervical, vaginal and vulvar cancer precursors connected with HPV types $6,11,16$ and 18, and dysplastic lesions and genital warts. The patients between the ages of 26 and 56 can be vaccinated by request. If these women have infection against vaccine types, they should be informed that it won't be protective against these types. HPV 16 and 18 are the main causes of $70 \%$ of cervical cancers. HPV 6 and 11 are the cause of about $90 \%$ of genital warts.

The most important obstacles in front of widely acceptance and application of the vaccine are high cost and insufficient information about the vaccine. The educational programs about HPV infection should be expanded the whole society.

As a result, the vaccine has been licensed in 107 countries, and 40 million doses were applied until December 2008, and it is recommended by most of organizations such as World Health Organization (WHO), United Nations Education and Science Organization (UNESCO), American College of Obstetrics and Gynecology (ACOG) and FDA. However, there are some questions to be answered about the vaccine, and ethical problems are still available. Therefore, the debates about whether the vaccination program has a priority or not in developing countries such as Turkey are going on.

\section{REFERENCES}

1. zur Hausen H, Gissmann L, Steiner W, et al. Human papilloma viruses and cancer. Bibl Haematol 43: 569$71,1975$. 
2. Parkin DM, Bray F. The burden of HPV-related cancers. Vaccine 24: 11-25, 2006.

3. Insinga RP, Dasbach EJ, Elbasha EH, et al. Incidence and duration of cervical human papilloma virus 6, 11, 16 and 18 infections in young women: an evaluation from multiple analytic perspectives. Cancer Epidemiol Biomarkers Prev 16: 709-711, 2007.

4. Smith JS, Lindsay L, Hoots B, et al. Human Papillomavirus type distrubution in invasive cervical cancer and highgrade cervical lesions: a meta-analysis update. Int J Cancer 3: 621-632, 2007.

5. Bosch FX, Lorincz AT, Munoz N, et al. The casual relation between human papilloma virus and cervical cancer. J Clin Pathol 55: 244-265, 2002.

6. Munoz M, Castellsague X, Berrington de Gonzalez, et al. HPV in the etiology of the human cancer. Vaccine 24: 1-10, 2006

7. Amanda T, Alison F. Human papillomavirus (including vaccines). Obstetr Gynecol Reprod Med 17: 324-329, 2007.

8. Stanley M. Immunobiology of HPV and HPV vaccines. Gynecol Oncol 109: 15-21, 2008.

9. Kjaer SK, Chackerian B, van den Brule AJ, et al. Highrisk human papilloma virus is sexually transmitted: evidence from a follow-up study of virgins starting sexual activity (intercourse). Cancer Epidemiol Biomarkers Prev 10: 101-106, 2001.

10. Molano M, van den Brule AJ, Plummer M, et al. Determinants of Clearance of Human Papillomavirusvinfections in Colombian Women with Normal Cytology: A Population-based 5 Year Follow-up Study. Am J Epidemiol 158: 486-94, 2003.

11. Mahdavi A, Monk JB. Vaccines against Human Papillomavirus and cervical cancer: Promises and challenges. The Oncologist 10: 528-538, 2005.

12. Frazer $\Perp$. Prevention of cervical cancer through papillomavirus vaccination. Nat Rev Immunol 4: 46-54, 2004.

13. Einstein $\mathrm{MH}$, Kadish AS, Burk RD, et al. Heat shock fusion protein -based immunotherapy fot treatment of cervical intraepithelial neoplasia 3. Gynecol Oncol 106: 453-460, 2007.

14. Coursaget P. Therapeutic Human Papillomavirus (HPV) Vaccines. HPV Today 4: 8-9, 2004.

15. Villa LL, Costa RLR, Petta CA, et al. Prophylactic quadrivalent human papillomavirus (types 6, 11, 16, and 18) $L 1$ virus-like particle vaccine in young women: a randomised double-blind placebo-controlled multicentre phase II efficacy trial. Lancet Oncol 6: 271-278, 2005.

16. Harper DM, Franco EL, Wheeler C, et al. Efficacy of a bivalent L1 virus-like particle vaccine in prevention of infection with human papillomavirus type 16 and 18 in young women: a randomised controlled trial. Lancet 364: 1757-1765, 2004.

17. Koutsky LA, Ault KA, Wheeler CM, et al. Proof of Principle Study Investigators. Controlled trial of a human papillomavirus type 16 vaccine. N Engl J Med 347: 1645-1651, 2002.
18. Harper DM, Franco EL, Wheeler C, et al. Sustained efficacy up to 4.5 years of a bivalent L1 virus-like particle vaccine against human papillomavirus type 16 and 18: follow-up from a randomised controlled trial. Lancet 367: 1247-1752, 2006.

19. Paavonen J, Naud P, Salmeron J, et al. Efficacy of human papillomavirus type 16 and 18 adjuvanted vaccine against cervical infection and precancer caused by oncogenic HPV types (PATRICIA): final analysis of a double-blind, randomised study in young women. Lancet 374: 301-314, 2009.

20. Koutsky LA, Ault KA, Wheeler CM, et al. Proof of Principle Study Investigators. Quadrivalent vaccine against human papillomavirus to prevent high grade cervical lesions. N Engl J Med 356: 1915-1927, 2007.

21. Kulasingam SL, Myers ER. Potential health and economic impact of adding a human papillomavirus vaccine to screening programs. JAMA 290: 781-789, 2003.

22. Winer RL, Lee SK, Hughes JP, et al. Genital human papillomavirus infection: incidence and risk factors in a cohort of female university students. J Epidemiol 157: 218-226, 2003.

23. Mao C, Koutsky LA, Ault KA, et al. Efficacy of human papillomavirus-16 vaccine to prevent cervical intraepithelial neoplasia: a randomised controlled trial. Obstet Gynecol 107: 18-27, 2006.

24. Carvalho ND, Martins CR, Teixeira J, et al. Immunogenicity and safety of the HPV 16/18 ASo4 adjuvanted vaccine up to 7.3 years. 25th International Papillomavirus Conference and Clinical Wokshop, May 8-14 May, 2009, Malmö, Sweden.

25. Franco EL, Harper DM. Vaccination against human papillomavirus infection: a new paradigm in cervical cancer control. Vaccine 23: 2388-2394, 2005.

26. Pinar G, Algier L, Colak M, Ayhan A. Jinekolojik hastalarda yaşam kalitesi. UHOD 18: 141-49, 2008.

27. Ferlay J, Bray F, Pisani P, Parkin DM. GLOBOCAN 2004. Cancer incidence, mortality and prevalence worldwide. IARC CancerBase No. 5, Version 2.0; IARC Press, Lyon, 2004.

\section{Correspondence}

Dr. Mustafa KARA

Bozok Üniversitesi Tıp Fakültesi

Adnan Menderes Caddesi No: 190

66200 YOZGAT / TURKEY

Tel: (+90.354) 2127001

Fax: (+90.354) 2122789

e-mail: mustafa.kara@bozok.edu.tr 